
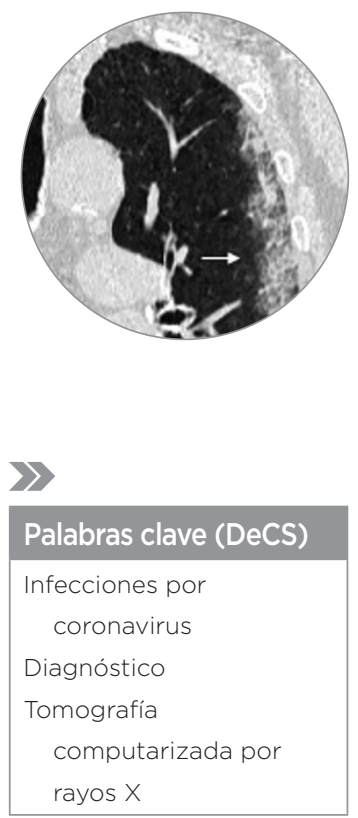

\section{Key words (MeSH)}

Coronavirus infections

Diagnosis

Tomography, X-Ray computed

\title{
Hallazgos imagenológicos y correlación con la escala de gravedad de la COVID-19
}

\author{
Imagenological Findings and Correlation with the Degree of Severity \\ of COVID-19
}

\author{
Jennifer Richardson Maturana' \\ Sindy Claudina Vergara Severiche ${ }^{2}$ \\ Juan Fernando Salcedo Brand ${ }^{3}$ \\ Camilo Andrés Ruiz Laverde ${ }^{4}$ \\ Claudia Cabarcas Herrera ${ }^{5}$
}

\section{Resumen}

El virus SARS-CoV-2 es el responsable de la pandemia actual, declarada como una emergencia de salud pública por la OMS, que inició en Wuhan, China, con los casos iniciales descritos como neumonía de origen desconocido. El virus sigue avanzando en su diseminación. A continuación, realizamos una revisión de la enfermedad desde sus características epidemiológicas, etiología, factores de riesgo, manifestaciones clínicas, hallazgos en laboratorio, en las imágenes por radiografía y tomografía computarizada. Algunas sociedades científicas proponen una correlación entre los hallazgos tomográficos y la cuantificación de la gravedad de la enfermedad.

\section{Summary}

The SARS-CoV-2 virus is responsible for the current pandemic, declared a public health emergency by the WHO, which began in Wuhan, China, with the initial cases described as pneumonia of unknown origin. The virus continues to spread. Next, we carry out a review of the disease from its epidemiological, etiology, clinical manifestations, laboratory findings and findings in radiography and computed tomography. Some societies propose a correlation between tomographic findings and the quantification of the severity of the disease.

\section{Introducción}

La pandemia actual —ocasionada por la infección por SARS-CoV-2 y la enfermedad asociada denominada COVID-19 - es una emergencia de salud pública, como ha sido declarado por la OMS, la cual empezó en Wuhan, China, con casos iniciales descritos como neumonía de origen desconocido. Actualmente, se registran casos en más de 188 países y el número de infectados y la mortalidad aumentan cada día; en algunos países ha llevado al colapso de los sistemas de salud, pues muchos de ellos no estaban preparados para manejar la situación al punto en que ha llegado. La tasa de mortalidad es variable, de acuerdo con la forma de presentación de la enfermedad - leve, moderada o grave- - en casos leves puede llegar al $1 \%$ y en casos moderados o graves, hasta el 10-35\%, por lo cual es clave identificar de manera temprana a estos pacientes mediante las manifestaciones clínicas, los estudios de laboratorio, el requerimiento de soporte ventilatorio, y los hallazgos por imágenes, las cuales han cobrado un papel importante como ayuda diagnóstica.

Aunque es poco lo que se ha descrito sobre la correlación de los hallazgos imagenológicos con la gravedad del cuadro clínico, la resolución de los hallazgos y la cronicidad del mismo.

\section{Epidemiología}

Desde su inicio en China, el mayor impacto en la mortalidad se ha registrado en Estados Unidos con más de 154.793 fallecimientos, lo que lo convierte en el país más afectado. El virus sigue avanzando en su diseminación alcanzando cifras ( 2 de agosto 2020) de más de 18 millones de casos en 188 países $(1,2)$, siendo los más afectados Estados Unidos, Brasil, India, Rusia y Sudáfrica.

A pesar de que la tasa de mortalidad por COVID-19 está alrededor del $1 \%$ en la población general (3), otros informes mencionan que son de hasta $10 \%$ y $35 \%$ (4). Entre los pacientes que progresan a enfermedad grave, la mortalidad hospitalaria alcanza a ser $\operatorname{del} 28 \%$ - mucho más alta que en otros informes que tenían datos de seguimiento incompletos - y mayor entre los pacientes que requirieron ventilación mecánica invasiva (5). En un estudio realizado por Auld y colaboradores, se encontró que entre 217 pacientes críticos, la mortalidad entre quienes requirieron ventilación mecánica fue del $35,7 \%$ (6). 
Los primeros datos de China sugieren que el grupo etario con más fallecimientos por COVID-19 es el de mayores de 60 años con comorbilidades graves, y entre personas de otras edades con afecciones de salud subyacentes graves. En el informe del 18 de marzo del Centro de Control y Prevención de Enfermedades (CDC, por sus siglas en inglés) de Estados Unidos, indican que la mortalidad es más alta en personas mayores de 85 años, con un rango del $10 \%$ al $27 \%$, seguido del $3 \%$ al $11 \%$ entre las personas de 65 a 84 años de edad; de $1 \%$ a $3 \%$ en personas de 55 a 64 años, $<1 \%$ entre personas de 20 a 54 años, y sin muertes entre personas de $\leq 19$ años (7).

En Colombia, en 90 días de ingreso del virus al país había 38.000 casos y 1.200 personas $(1,1 \%)$ fallecidas, la mayor parte con edades entre 50- 60 años. Actualmente hay más de 300.000 casos confirmados y más de 10.000 fallecidos (3\%) (8).

\subsection{Etiología}

El SARS-CoV-2 es un virus de ARN de cadena positiva que pertenece a la familia Coronaviridae, del orden Nidovirales, subfamilia Orthocoronavirinae y esta, a su vez, se clasifica en cuatro géneros Alphacoronavirus $(\alpha \mathrm{CoV})$, Betacoronavirus ( $(\mathrm{CoV})$, Deltacoronavirus $(\delta \mathrm{CoV})$ y Gammacoronavirus $(\gamma \mathrm{CoV})$. Se ha determinado que el SARS-CoV-2 hace parte de los $\beta \mathrm{CoV}$ y la fuente de estos, así como los $\alpha \mathrm{CoV}$, son probablemente murciélagos y roedores (9).

Se ha demostrado que dentro de los coronavirus que afectan humanos, el SARS-CoV, SARS-CoV-2 y MERS-CoV ( $ß \mathrm{CoV}$ del linaje B y C, respectivamente), son los responsables de epidemias con gravedad clínica variable que presentan manifestaciones respiratorias y extrarrespiratorias. En relación con el SARS-CoV y el MERS-CoV, las tasas de mortalidad son de hasta $10 \%$ y $35 \%$, respectivamente (9).

En un estudio realizado por Chan y colaboradores, describen que el genoma de 2019-nCoV tiene una identidad general de nucleótidos del $89 \%$ con el CoV relacionado con el SARS de murciélago SL-CoVZXC21, y el $82 \%$ con el SARS-CoV BJ01 2003 humano y el SARS$\mathrm{CoV}$ Tor2 humano. Algunos estudios sugieren que ciertos huéspedes intermediarios podrían ser diferentes mamíferos, como los visones, así como algunos otros mamíferos; sin embargo, esto no está claro hasta el momento (10).

Al igual que el SARS, se ha demostrado que el SARS-CoV-2 usa como receptor la enzima convertidora de angiotensina 2 (ACE2), la unidad de superficie (S1) se une a esta, posteriormente usa la serina proteasa del huésped (TMPRSS2), lo que permite la entrada del virus a la célula. Este virus principalmente invade las células del epitelio alveolar lo que resulta en síntomas de origen respiratorio. Dado que la ACE2 se expresa principalmente en los pulmones y en el corazón, se ha sugerido que la presentación más grave de los síntomas en los pacientes con patologías cardiovasculares puede ser por este tropismo del virus (11). La patogenia principal de la infección por SARS-CoV-2, como virus dirigido al sistema respiratorio, es la neumonía grave, combinada con la incidencia de opacidades en vidrio esmerilado y daño cardiaco agudo (12).

\subsection{Factores de riesgo y manifestaciones clínicas}

Los factores de riesgo comunes incluyen: edad mayor de 65 años, enfermedad cardiovascular, diabetes, enfermedad respiratoria crónica, hipertensión y estado de inmunosupresión. Si el paciente infectado por
COVID-19 presenta una o varias de estas comorbilidades le confiere un mayor nivel de riesgo de complicaciones desde el punto de vista clínico (13).

Se cree que el COVID-19 tiene un periodo de incubación de 14 días a partir de la exposición $(14,15)$, pero desarrolla síntomas entre los 2,2 y 11,5 días (4).

Afecta a personas de cualquier edad, pero con mayor frecuencia a adultos de mediana edad y mayores $(15,16)$. Los síntomas en niños suelen ser leves, similares a los de los adultos (17), aunque se han informado casos de gravedad $(18,19)$ en los cuales los pacientes desarrollan el síndrome inflamatorio multisistémico (con o sin criterios de enfermedad de Kawasaki) (20).

Los casos fatales han ocurrido en personas de edad avanzada o con comorbilidades médicas subyacentes (21).

Se han descrito infecciones asintomáticas, cuya frecuencia es desconocida (22); sin embargo, tienen anormalidades clínicas que pueden ser identificadas. Hu y colaboradores les realizaron tomografía de tórax a 24 pacientes asintomáticos, de los cuales el 50 \% mostró alteraciones compatibles con la infección por imagen; desarrollaron síntomas leves pocos días después del diagnóstico (23). Bandirali y colaboradores describen en una serie de 170 pacientes, que el $59 \%$ de los pacientes asintomáticos o mínimamente sintomáticos pueden tener radiografías de tórax con hallazgos de infección después de 14 días de cuarentena (24).

No existen características clínicas específicas que distingan al COVID-19 de otras infecciones virales $(22,25,26)$.

El curso de la sintomatología puede variar en un rango desde asintomático que progresa a síntomas leves y posterior desarrollo de disnea con requerimiento de admisión hospitalaria, los estudios varían en cuanto a los tiempos en los que esto puede ocurrir, entre 7 y 8 días $(15,27)$.

El debut de la enfermedad incluye fiebre en la mayoría de los pacientes (99\%), tos seca (59\%), fatiga (70\%), anorexia (40\%), mialgias $(40 \%)$, disnea $(31 \%)$, tos con esputo $(27 \%)(15,28,29)$.

Otros síntomas menos comunes incluyen cefalea, odinofagia y rinorrea. Se han descrito también síntomas gastrointestinales, como náuseas y diarrea, con menor frecuencia $(15,27)$.

Los pacientes graves cursan con neumonía caracterizada por fiebre, tos, disnea y opacidades bilaterales en las imágenes de tórax $(15,27)$.

Los pacientes críticos presentan disfunción multiorgánica con falla ventilatoria y requerimiento de ventilación mecánica en unidad de cuidado intensivo. Una de las complicaciones más importantes en el paciente crítico es el síndrome de dificultad respiratoria aguda (SDRA) observada entre el 12-41\% de los pacientes estudiados (27,30). Otras complicaciones son las arritmias, lesión cardiaca aguda y choque (27).

La OMS informa que, al parecer, el tiempo de recuperación es de dos semanas para infecciones leves y de tres a seis semanas para enfermedades graves; sin embargo, aún faltan estudios para determinar esto con exactitud, así como las consecuencias a largo plazo (31).

\subsection{Manifestaciones de laboratorios}

El recuento de glóbulos blancos es variable entre leucocitosis, leucopenia y linfopenia, y esta última es más común $(15,27)$; se presenta con niveles elevados de lactato deshidrogenasa, ferritina y aminotransferasas. La procalcitonina puede ser normal al ingreso y elevarse a medida que avanza la infección $(15,28)$. 
La mortalidad se ha asociado a niveles altos de dímero $\mathrm{D}$ y a linfopenia grave (27).

\section{Diagnóstico}

El diagnóstico se realiza mediante la RT-PCR en muestras aisladas de secreciones del tracto respiratorio obtenidas por lavado broncoalveolar, hisopado orofaríngeo o sangre. El resultado se obtiene en un lapso de 15 minutos a 8 horas, dependiendo de la técnica utilizada (32). Esta prueba tiene una sensibilidad del 60-70\% con un elevado número de falsos negativos, por lo cual, algunas guías recomiendan para el diagnóstico inicial los hallazgos tomográficos asociados a las manifestaciones clínicas (33).

La tomografía computarizada (TC) comenzó a utilizarse como prueba diagnóstica en algunas regiones, por falta del reactivo para la detección química. Dada la poca disponibilidad global de esta y la exposición a radiación, sociedades radiológicas como la ACR (34), BSTI (35) y la SERAM (36), desaconsejan su uso para diagnóstico o tamizaje. La Sociedad Fleischner dice que, basados en la experiencia de los panelistas y pese a las recomendaciones de otras sociedades, muchos sí utilizan las imágenes para diagnóstico, en especial en los pacientes con una alta probabilidad clínica previa, ya que estas podrían revelar un diagnóstico alternativo a COVID-19, y el manejo se basa en pautas establecidas o en la práctica clínica estándar; además, resalta que la sensibilidad es mayor en el contexto de poca disponibilidad de pruebas diagnósticas, así como tiempos de espera prolongados que retrasan el manejo de los pacientes.

Los hallazgos radiológicos por TC tienen una sensibilidad del $94 \%$. $\mathrm{Su}$ especificidad es baja, porque los patrones radiológicos en la $\mathrm{CO}-$ VID-19 se solapan con los encontrados en otras infecciones respiratorias virales, como el H1N1, MERS y SARS, entre otros. La radiografía y la tomografía computarizada tienen una mayor sensibilidad en la medida de la gravedad clínica del paciente, dado que en este punto los hallazgos imagenológicos son evidentes. El $50 \%$ de los estudios por imagen pueden ser normales, cuando el paciente se encuentra en fases iniciales de la enfermedad o presenta una sintomatología nula o leve (37).

El consenso de la Sociedad Fleischner (32) hace recomendaciones para el uso de la radiografía y tomografía de tórax en adultos, dado que a la fecha de su publicación los niños no presentaban infecciones graves; sin embargo, revisiones posteriores describen hallazgos radiológicos en los niños similares a los de los adultos; resaltan una mayor prevalencia de consolidaciones con halo reverso en este grupo etario (33).

La radiografía de tórax es insensible en la infección leve o temprana por COVID-19 (34); sin embargo, en pacientes hospitalizados, tanto la radiografía de tórax como la tomografía pueden ser útiles para evaluar la progresión de la enfermedad y llegar a diagnósticos alternativos (por ejemplo, neumonía lobar sugestiva de sobreinfección bacteriana, neumotórax y derrame pleural) (38).

En un paciente que inicialmente tenga una PCR negativa, con hallazgos imagenológicos altamente sugestivos de COVID-19, se debe realizar nuevamente la PCR para confirmar o descartar la infección (38).

Si el paciente es asintomático, pero tiene hallazgos radiológicos altamente sugestivos de la infección, se sugiere realizar la prueba PCR (39) para identificar potencialmente una infección oculta y limitar la transmisión adicional en la comunidad y en el entorno donde el paciente recibe atención médica.

\subsection{Imágenes}

El paciente candidato a tomografía es el que presenta criterios clínicos de gravedad, empeoramiento rápidamente progresivo, en quien se requiere detectar complicaciones y plantear diagnósticos alternativos, por lo tanto, esta decisión es individualizada (35).

Sobre la adquisición, Nakajima y colaboradores recomiendan realizar idealmente cortes finos, como los utilizados para la TACAR (colimación 1-1,5 mm), con el fin de caracterizar adecuadamente los detalles finos dada su alta resolución; también se debe realizar en decúbito supino y en inspiración final. No es necesario el uso de medio de contraste y se deben valorar las proyecciones axiales y coronales (40).

La terminología recomendada para las descripciones es la que se utiliza en el glosario de Fleischner, con el fin de unificar un lenguaje radiológico claro (37).

Los hallazgos imagenológicos descritos hasta ahora como típicos son: el patrón en vidrio esmerilado, el cual suele ser el primer hallazgo tanto en radiografía simple como en TC, con incidencias de 85,49 \%; la distribución mayoritariamente periférica y subpleural (incidencia $76,95 \%$ ) con predominio hacia los lóbulos inferiores en segmentos posteriores y con menor frecuencia dentro del lóbulo medio derecho (figura 1). Inicialmente puede ser unilateral, y luego se observa un compromiso bilateral (incidencia 81,80\%). Puede haber, menos comúnmente, engrosamiento de los septos interlobulillares (48,46\%) (figura 2), bronquiectasias y engrosamiento pleural (52,46\%), en etapas posteriores de la enfermedad conforme progresa y aumenta la gravedad se pueden ver pacientes con patrón en empedrado o "crazy paving" como se denomina en inglés (figura 3), (14,81\%) $(39,41)$.

Las consolidaciones indican gravedad, por lo tanto, si la TC inicial tiene estos hallazgos se trata de un paciente grave (figura 4). Su distribución es la descrita para el vidrio esmerilado y, de hecho, se solapa con este en un número menor de casos, con mayor frecuencia en los ancianos (43).

En la mayor parte de la literatura revisada se describen como hallazgos menos frecuentes, que pueden observarse según la progresión de la enfermedad, el derrame pleural o pericárdico, las linfadenopatías, cavitaciones, el neumotórax, el halo reverso o signo del atolón (figura 5) y la dilatación bronquial con engrosamiento de la pared (figura 6) (44).

A continuación, se describen algunas pautas publicadas por diferentes entidades internacionales, para la evaluación imagenológica.

La Sociedad Fleischner plantea tres escenarios según la clínica y la disponibilidad de recursos. Se destaca la recomendación de realizar imágenes radiológicas en los pacientes con manifestaciones clínicas moderadas-graves, independientemente del resultado de la prueba de la COVID-19, ya que establecen el estado pulmonar basal y ayudan a identificar anormalidades cardiopulmonares subyacentes o incluso causadas por la misma infección, y que pueden facilitar la estratificación del riesgo, además de que deben hacerse en el paciente que cursa con empeoramiento clínico.

Por otro lado, se han desarrollado múltiples clasificaciones por las diferentes sociedades para informar los hallazgos tomográficos en los pacientes con sospecha o diagnóstico de COVID-19; se recomienda que el uso de una u otra sea concertado por el equipo clínico de trabajo. En Colombia, las que tienen mayor aceptación son la de Simpson, la de la Sociedad Británica de Imagen Torácica y la de Diagnosis and treatment protocol for novel coronavirus pneumonia. 


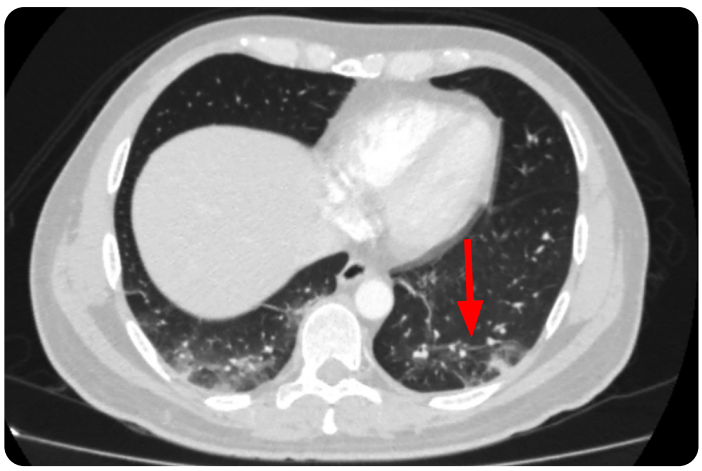

Figura 1. TC axial de tórax. Paciente de 50 años de edad con nexo epidemiológico, se visualizan opacidades en vidrio esmerilado distribuidas de forma periférica (flecha)

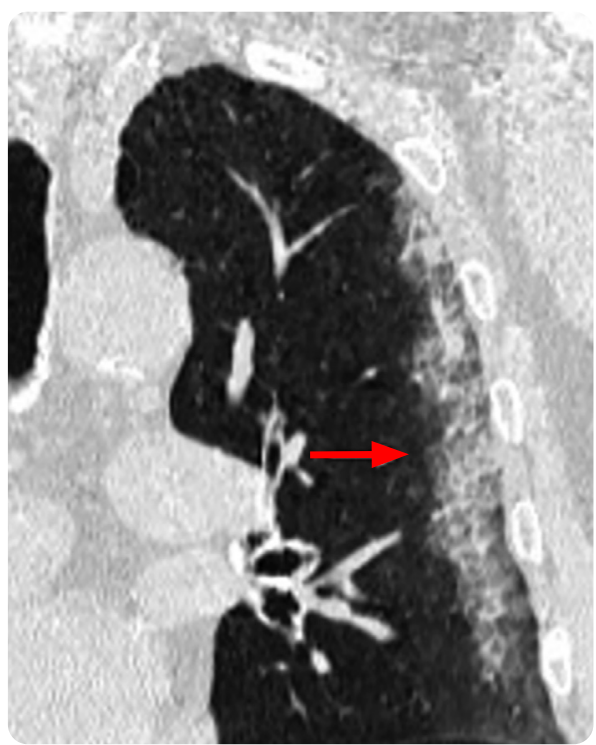

Figura 2. TC de tórax, axial. Engrosamiento de los septos interlobulillares de forma periférica (flecha)

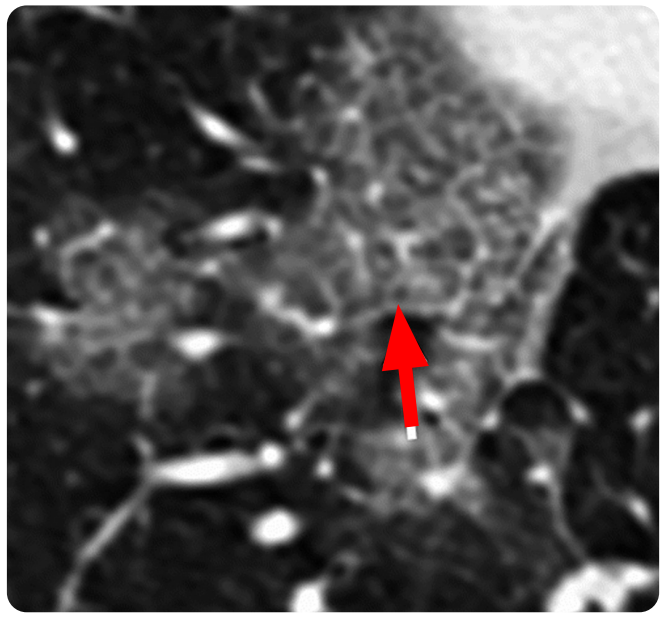

Figura 3. Patrón en empedrado. TC axial, sin medio de contraste. Paciente de 65 años de edad con antecedente de viaje reciente a Wuhan, con con fiebre y tos productiva. Se observa patrón en empedrado, que se caracteriza por opacidad en vidrio esmerilado asociado a engrosamiento de los septos interlobulillares hacia el lóbulo inferior derecho.

Fuente: Tomado con permiso de publicación de Chung y colaboradores (42).

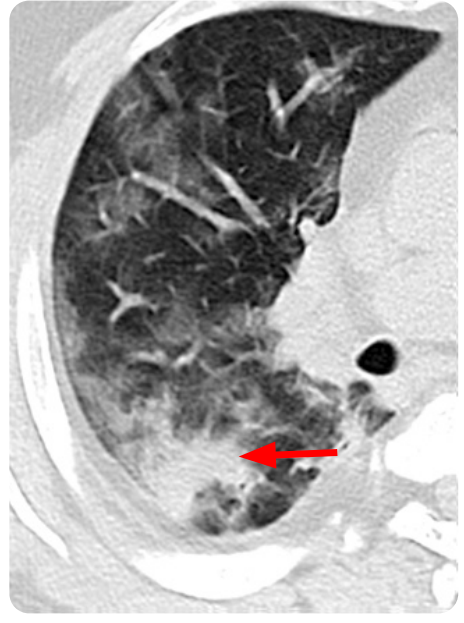

Figura 4. TC de tórax. Paciente de 34 años de edad, se observa consolidación basal derecha (flecha).

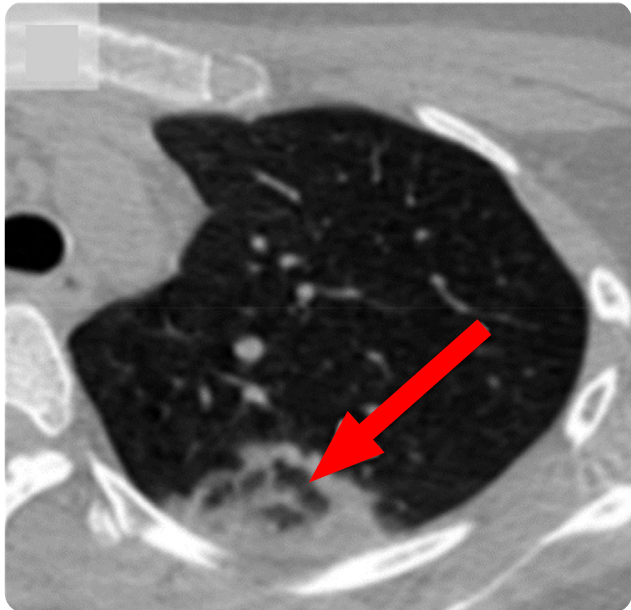

Figura 5. Signo del halo reverso. TC axial. Mujer de 22 años de edad. Se observa un área de opacidad en vidrio esmerilado con un anillo denso de consolidación hacia el lóbulo superior izquierdo (flecha). Este hallazgo corresponde al signo del halo reverso.

Fuente: Tomado con permiso de publicación de Bernheim y colaboradores. (45),

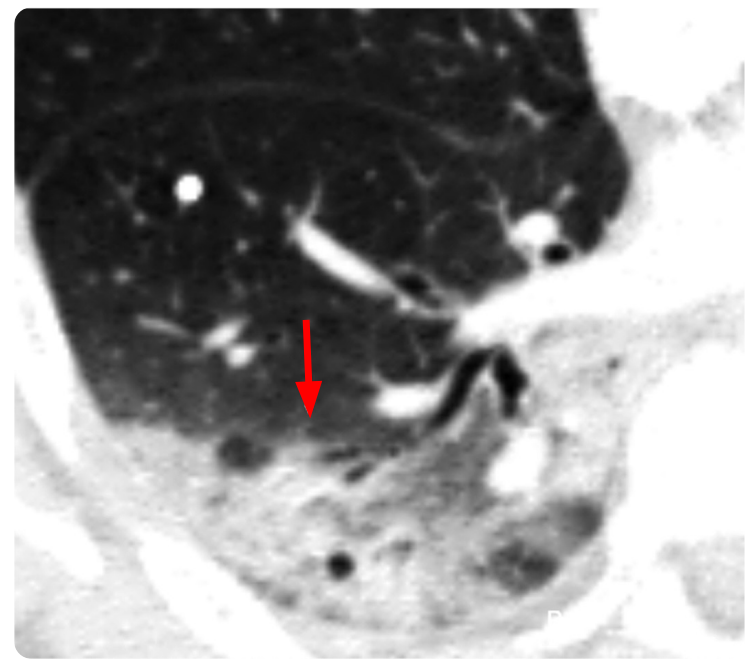

Figura 6. TC axial de tórax. Paciente de 58 años de edad, con sospecha de infección por COVID 19, que demuestra dilatación bronquial y engrosamiento de las paredes bronquiales. 


\section{Tabla 1. Lenguaje propuesto para el informe de hallazgos tomográficos relacionados con la COVID-19}

\begin{tabular}{|c|c|c|c|}
\hline $\begin{array}{l}\text { Clasificación } \\
\text { imagenológica } \\
\text { de neumonía } \\
\text { por COVID-19 }\end{array}$ & Fundamentos & Hallazgos tomográficos & $\begin{array}{l}\text { Lenguaje sugerido para el } \\
\text { informe }\end{array}$ \\
\hline Apariencia típica & $\begin{array}{l}\text { Hallazgos } \\
\text { imagenológicos } \\
\text { comúnmente } \\
\text { informados con } \\
\text { mayor especificidad } \\
\text { para neumonía por } \\
\text { COVID-19. }\end{array}$ & $\begin{array}{l}\text { Áreas de vidrio esmerilado periférico, bilateral con o } \\
\text { sin consolidación, o septos interlobulillares (patrón en } \\
\text { empedrado). } \\
\text { Áreas de vidrio esmerilado multifocal de morfología } \\
\text { redondeada con o sin consolidación, o septos } \\
\text { interlobulillares (patrón en empedrado). } \\
\text { Signo del halo reverso y otros hallazgos de neumonía de } \\
\text { organización (visto posteriormente en la enfermedad). }\end{array}$ & $\begin{array}{l}\text { "Se encuentran hallazgos comúnmente } \\
\text { informados en neumonía por COVID-19. Otros } \\
\text { procesos, como la influenza y neumonía de } \\
\text { organización, como puede ser visto en } \\
\text { toxicidad por drogas y enfermedades del } \\
\text { tejido conectivo, pueden causar un patrón } \\
\text { imagenológico similar". }\end{array}$ \\
\hline $\begin{array}{c}\text { Apariencia } \\
\text { indeterminada }\end{array}$ & $\begin{array}{l}\text { Hallazgos no } \\
\text { específicos de } \\
\text { neumonía por } \\
\text { COVID-19. }\end{array}$ & $\begin{array}{l}\text { Ausencia de características típicas y presencia de: } \\
\text { Áreas de vidrio esmerilado multifocal, difuso, perihiliar } \\
\text { o unilateral con o sin consolidación, sin una distribución } \\
\text { específica y no son redondeadas o no periféricas. Algunas } \\
\text { áreas pequeñas de vidrio esmerilado con una distribución } \\
\text { no periférica, no redondeadas. }\end{array}$ & $\begin{array}{l}\text { "Se encuentran hallazgos imagenológicos } \\
\text { que pueden ser vistos en neumonía por } \\
\text { COVID-19; sin embargo, no son específicos } \\
\text { y pueden ocurrir con una variedad de } \\
\text { procesos infecciosos o no infecciosos". }\end{array}$ \\
\hline Atípico & $\begin{array}{l}\text { Hallazgos poco } \\
\text { comunes o no } \\
\text { informados en } \\
\text { neumonía por } \\
\text { COVID-19. }\end{array}$ & $\begin{array}{l}\text { Ausencia de hallazgos típicos o indeterminados y } \\
\text { presencia de: } \\
\text { Consolidación lobar aislada o segmentaria sin vidrio } \\
\text { esmerilado. } \\
\text { Nódulos pequeños (centrilobulillares, "árbol en } \\
\text { gemación"). } \\
\text { Cavitación pulmonar. } \\
\text { Engrosamiento liso de los septos interlobulillares con } \\
\text { derrame pleural. }\end{array}$ & $\begin{array}{l}\text { "Se encuentran hallazgos imagenológicos } \\
\text { que han sido informados de manera atípica } \\
\text { en neumonía por COVID-19 (se deben } \\
\text { considerar diagnósticos alternos)". }\end{array}$ \\
\hline $\begin{array}{l}\text { Negativo para } \\
\text { neumonía }\end{array}$ & $\begin{array}{l}\text { No hay hallazgos de } \\
\text { neumonía. }\end{array}$ & No hay hallazgos tomográficos que sugieran neumonía. & $\begin{array}{l}\text { "No se encuentran hallazgos tomográficos } \\
\text { que indiquen neumonía. (Nota: La TC } \\
\text { de tórax puede ser negativa en etapas } \\
\text { tempranas de neumonía por COVID-19)". }\end{array}$ \\
\hline
\end{tabular}

Notas: 1. La inclusión en un informe de los ítems anotados entre paréntesis en la columna de "Lenguaje sugerido para el informe", puede depender de la sospecha clínica, la prevalencia local, el estado del paciente y los procedimientos locales con respecto al informe. 2 . La TC no es un sustituto de la RT-PCR, considere realizar pruebas de acuerdo con las recomendaciones y procedimientos locales y la disponibilidad de RT-PCR.

Fuente: Tomada y traducida de Simpson et al. (34).

La Sociedad Británica de Imagen Torácica (BSTI, por las iniciales en inglés de British Society of Thoracic Imaging) clasifica en tres categorías clínico-radiológicas a los pacientes en el entorno de la COVID-19, y hace una cuantificación de la gravedad de la enfermedad (46).

Tabla 2. Correlación entre los hallazgos radiológicos y la cuantificación de la gravedad clínica

\begin{tabular}{|c|c|c|c|}
\hline & Hallazgos & $\begin{array}{l}\text { Cambios en el } \\
\text { parénquima pulmonar }\end{array}$ & Gravedad \\
\hline \multirow{3}{*}{ Sugerentes de infección COVID-19 } & Opacidades periféricas en vidrio esmerilado & Hasta 3 anomalías focales $<3 \mathrm{~cm}$ & Moderada \\
\hline & $\begin{array}{l}\text { Patrón alveolar difuso } \\
\text { Patrón en empedrado } \\
\text { Neumonía organizativa }\end{array}$ & Más de 3 anomalías focales o $>3 \mathrm{~cm}$ & Moderado/grave \\
\hline & Distorsión de la arquitectura & & Grave \\
\hline \multirow{2}{*}{$\begin{array}{l}\text { Indeterminado de infección } \\
\text { COVID-19 }\end{array}$} & \multirow{2}{*}{$\begin{array}{l}\text { Opacidades periféricas en vidrio esmerilado/ } \\
\text { parcheadas/no periféricas } \\
\text { Fibrosis con vidrio esmerilado } \\
\text { Derrame pleural } \\
\text { Adenopatías } \\
\text { Patrones complejos }\end{array}$} & Hasta 3 anomalías focales $<3 \mathrm{~cm}$ & Moderada \\
\hline & & Más de 3 anomalías focales $0>3 \mathrm{~cm}$ & Moderada/grave \\
\hline $\begin{array}{l}\text { Poco probables de infección } \\
\text { COVID-19 }\end{array}$ & $\begin{array}{l}\text { Neumonía lobar } \\
\text { Infecciones cavitadas } \\
\text { Patrón en árbol en gemación }\end{array}$ & & \\
\hline
\end{tabular}

Fuente: Adaptada de The British Institut of Radiology $(37,47)$. 
Lo expuesto en la tabla 2 demuestra que los pacientes con clínica leve generalmente tienen lesiones con un diámetro en eje largo menores a $3 \mathrm{~cm}$ y se caracterizan por ser lesiones en vidrio esmerilado. Quienes presenten en las imágenes consolidaciones, patrón en vidrio esmerilado y consolidación, patrón en empedrado o distorsión de la arquitectura, y/o estas lesiones midan más de $3 \mathrm{~cm}$ en eje largo, son pacientes con un estado clínico moderado/severo. Zhon y colaboradores encontraron hallazgos similares en su estudio (48).

La BSTI también recomienda extender el estudio tomográfico del tórax, si en un TC de abdomen se encuentran hallazgos pulmonares basales.

La gravedad de la COVID-19 se categoriza como leve, moderada, grave o crítico, según la ausencia o presencia de disfunción o daño pulmonar significativo, y otros parámetros clínicos especificados en la tabla 3 (49).

\section{Tabla 3. Criterios clínicos de gravedad de la infección COVID-19}

\begin{tabular}{|c|c|}
\hline Tipos & Hallazgos \\
\hline Leve & $\begin{array}{l}\text { Síntomas clínicos leves (fiebre } \leq 38^{\circ} \mathrm{C} \text { (sin tratamiento), } \\
\text { con o sin tos, sin disnea, sin enfermedades crónicas. }\end{array}$ \\
\hline Moderado & Fiebre, síntomas respiratorios, imágenes de neumonía. \\
\hline Grave & $\begin{array}{l}\text { Cualquiera de los siguientes: } \\
\text { Distrés respiratorio, } \mathrm{FR} \geq 30 / \mathrm{min} \text {. } \\
\mathrm{SpO} 2 \leq 93 \% \text { en reposo. } \\
\mathrm{PaO} 2 / \mathrm{FiO} 2 \leq 300 \mathrm{~mm} \mathrm{Hg} \text {. } \\
\text { Progresión rápida por imágenes entre las } 24-48 \mathrm{~h} \text {. }\end{array}$ \\
\hline Crítico & $\begin{array}{l}\text { Cualquiera de los siguientes: } \\
\text { Falla respiratoria, con requerimiento de ventilación } \\
\text { mecánica. } \\
\text { Choque. } \\
\text { Falla multiorgánica, internación en } \mathrm{UCl} \text {. }\end{array}$ \\
\hline
\end{tabular}

Abreviaturas: FR: Frecuencia respiratoria. $\mathrm{SpO}_{2}$ : Saturación de oxígeno. $\mathrm{PaO}_{2}$ : Presión parcial de oxígeno. $\mathrm{FiO}_{2}$ : Fracción de oxígeno inspirado.

Fuente: Adaptada de Diagnosis and treatment protocol for novel coronavirus pneumonia (Trial version 7) (49).

Adicionalmente, se han descrito los hallazgos radiológicos relacionados con el curso clínico de la infección en el tiempo, en los que se han observado en estadios tempranos (de 0-4 días) cambios dados por opacidades en vidrios esmerilado, empedrado irregular y pocos lóbulos comprometidos; en estadio progresivo (aproximadamente de 5-8 días), se asocia con cambios dados por aumento tanto en la extensión como en el número de lesiones por vidrio esmerilado y del empedrado irregular, con mayor compromiso de lóbulos directamente relacionado con el grado de severidad (44); en el estadio máximo (9-13 días), se relaciona con la aparición de consolidaciones, y en estadio de regresión (más de 14 días), se asocia con disminución de los hallazgos y resolución gradual (50).
Las imágenes de TC de seguimiento mostraron que las lesiones son migratorias: se manifiestan como la absorción de las lesiones primarias y la aparición de nuevas lesiones, que aún no se habían informado (51).

Resumiendo, la progresión imagenológica muestra inicialmente el patrón descrito en vidrio esmerilado, seguido por el engrosamiento de los septos interlobulillares y las consolidaciones. El patrón en empedrado y las consolidaciones son patrones sugestivos de que el paciente se encuentra grave o en estado crítico y suelen verse a los 10 días del inicio de los síntomas (50). Los pacientes en quienes se considera el egreso hospitalario deben tener estabilidad clínica, con resolución de los síntomas y una RT-PCR negativa (49).

\section{Seguimiento}

Actualmente no hay indicación de realizar estudios de imagen para evaluar la resolución de la enfermedad; sin embargo, se ha descrito que los pacientes con mejoría clínica muestran resolución gradual de las consolidaciones, así como disminución en el númerotamaño de las lesiones y lóbulos comprometidos, parámetros que se consideran determinantes para la evaluación de la gravedad de la enfermedad, lo cual indica la importancia de realizar la descripción de estos hallazgos de manera precisa desde los estudios imagenológicos iniciales.

No se han demostrado diferencias significativas (mortalidad, duración de la estadía y días de ventilación) en la realización diaria de radiografías para los pacientes en UCI (52).

Aún está en investigación el tiempo de resolución de los hallazgos por imagen, aunque algunos artículos hablan de resolución en aproximadamente 2 semanas. Así mismo, están bajo estudio las lesiones pulmonares que indican cronicidad, algunos autores describen que la fibrosis residual puede estar relacionada con esta última (44).

\section{Conclusión}

La infección por SARS-CoV-2 ha aumentado de forma exponencial y aunque su mortalidad es baja en la población general, en la población de alto riesgo (pacientes ancianos $>$ de 60 años y con comorbilidades) es alta. La gravedad clínica es variable desde el punto de vista de las manifestaciones pulmonares y extrapulmonares. Conocer los hallazgos radiológicos es importante para el diagnóstico, más aún cuando no se cuenta con RT-PCR o el resultado no está disponible en los días inmediatos. Es importante realizar un informe estructurado, tener en cuenta las comorbilidades, intentar reconocer los hallazgos radiológicos y proponer un grado de gravedad en el informe radiológico. En esta revisión se da a conocer la importancia de reconocer la clasificación de gravedad, de acuerdo con los hallazgos de imágenes, que pueden servir de ayuda para conocer el estado en que se encuentra la enfermedad y, adicionalmente, la respuesta al tratamiento. Se propone, entonces, que en futuras investigaciones se pueda demostrar la relación de los hallazgos imagenológicos con los parámetros ventilatorios (por ejemplo, niveles de $\mathrm{PaFio}_{2}$ ), para conocer el estado de la enfermedad y la respuesta al tratamiento. 


\section{Referencias}

1. Mapa del coronavirus en el mundo, en tiempo real hoy: casos, infectados y muertos - AS.com [internet]. 2020 [citado: 2020 mar. 26]. Disponible en: https:// as.com/diarioas/2020/03/20/actualidad/1584685922_058257.html

2. John Hopkins University and Medicine. Johns Hopkins Coronavirus Resource Center [internet]. 2020 [citado: 2020 mar. 26]. Disponible en: https://coronavirus. jhu.edu/map.html

3. Coronavirus COVID-19 Global Cases Map by Johns Hopkins Center for Systems Science and Engineering Estadísticas. PR [internet]. 2020 [citado: 2020 mar. 26]. Disponible en: https://estadisticas.pr/en/media/3341

4. Lauer SA, Grantz KH, Bi Q, Jones FK, Zheng Q, Meredith HR, et al. The incubation period of coronavirus disease 2019 (COVID-19) from publicly reported confirmed cases: estimation and application. Ann Intern Med. 2020;172(9):57782. doi: $10.7326 / \mathrm{M} 20-0504$

5. Worldometer. Coronavirus edad, sexo, demografía (COVID-19) [internet]. 2020 [citado: 2020 mar. 27]. Disponible en: https://www.worldometers.info/ coronavirus/coronavirus-age-sex-demographics/

6. Auld SC, Caridi-Scheible M, Blum JM, Robichaux C, Kraft C, Jacob JT, et al. ICU and ventilator mortality among critically ill adults with coronavirus disease 2019. Crit Care Med. 2020. doi: 10.1097/CCM.0000000000004457

7. Bialek S, Boundy E, Bowen V, Chow N, Cohn A, Dowling N, et al. Severe outcomes among patients with coronavirus disease 2019 (COVID-19), United States, February 12-March 16, 2020. MMWR Morb Mortal Wkly Rep. 2020;69(12):343-6.

8. Confirman primera muerte por COVID-19 en Colombia y 14 nuevos casos [internet]. [citado: 2020 mar. 22]. Disponible en: http://www.redmas.com.co/ salud/confirman-primera-muerte-covid-19-colombia-14-nuevos-casos/

9. Cascella M, Rajnik M, Cuomo A, Dulebohn SC, Napoli R Di. Features, evaluation and treatment coronavirus (COVID-19). StatPearls. 2020.

10. Chan JF-WW, Kok K-HH, Zhu Z, Chu H, To KK-WW, Yuan S, et al. Genomic characterization of the 2019 novel human-pathogenic coronavirus isolated from a patient with atypical pneumonia after visiting Wuhan. Emerg Microbes Infect. 2020;9(1):221-36.

11. Zheng Y-Y, Ma Y-T, Zhang J-Y, Xie X. COVID-19 and the cardiovascular system. Nat Rev Cardiol. 2020;1-2

12. Rothan HA, Byrareddy SN. The epidemiology and pathogenesis of coronavirus disease (COVID-19) outbreak. J Autoimmun [internet]. 2020 Feb;102433. Disponible en: https://linkinghub.elsevier.com/retrieve/pii/S0896841120300469

13. Wu Z, McGoogan JM. Characteristics of and important lessons from the coronavirus disease 2019 (COVID-19) Outbreak in China: Summary of a Report of 72314 Cases from the Chinese Center for Disease Control and Prevention. JAMA J Am Med Assoc. 2020.

14. Li Q, Guan X, Wu P, Wang X, Zhou L, Tong Y, et al. Early transmission dynamics in Wuhan, China, of novel coronavirus-infected pneumonia. N Engl J Med. 2020.

15. Huang C, Wang Y, Li X, Ren L, Zhao J, Hu Y, et al. Clinical features of patients infected with 2019 novel coronavirus in Wuhan, China. Lancet. 2020;395(10223):497-506.

16. Wang D, Hu B, Hu C, Zhu F, Liu X, Zhang J, et al. Clinical characteristics of 138 hospitalized patients with 2019 novel coronavirus-infected pneumonia in Wuhan, China. JAMA. 2020;323(11):1061-9.

17. Qiu H, Wu J, Hong L, Luo Y, Song Q, Chen D. Clinical and epidemiological features of 36 children with coronavirus disease 2019 (COVID-19) in Zhejiang, China: an observational cohort study. Lancet Infect Dis [internet]. 2020. Disponible en: https://linkinghub.elsevier.com/retrieve/pii/S1473309920301985

18. Cui Y, Tian M, Huang D, Wang X, Huang Y, Fan L, et al. A 55-Day-Old Female Infant infected with COVID 19: presenting with pneumonia, liver injury, and heart damage. J Infect Dis [internet]. 2020. doi: 10.1093/infdis/jiaa113

19. Jiehao C, Jing X, Daojiong L, Zhi Y, Lei X, Zhenghai Q, et al. Case series of children with 2019 novel coronavirus infection: clinical and epidemiological features. Clin Infect Dis. [citado: 2020 mar. 26]. Disponible en: https://academic. oup.com/cid/ advance-article-abstract/doi/10.1093/cid/ciaa198/5766 430

20. Belhadjer Z, Méot M, Bajolle F, Khraiche D, Legendre A, Abakka S, et al. Acute heart failure in multisystem inflammatory syndrome in children (MIS-C) in the context of global SARS-CoV-2 pandemic. Circulation. 2020.

21. Zhou F, Yu T, Du R, Fan G, Liu Y, et al. Clinical course and risk factors for mortality of adult inpatients with COVID-19 in Wuhan, China: a retrospective cohort study. Lancet. 2020;0(0).

22. Chan JFW, Yuan S, Kok KH, To KKW, Chu H, Yang J, et al. A familial cluster of pneumonia associated with the 2019 novel coronavirus indicating person-to-person transmission: a study of a family cluster. Lancet. 2020;395(10223):514-23.

23. Hu Z, Song C, Xu C, Jin G, Chen Y, Xu X, et al. Clinical Characteristics of 24 Asymptomatic Infections with COVID-19 Screened among Close Contacts in Nanjing, China. medRxiv. 2020 Feb;2020.02.20.20025619.

24. Bandirali M, Sconfienza LM, Serra R, Brembilla R, Albano D, Ernesto PF, et al. Chest $\mathrm{X}$-ray findings in asymptomatic and minimally symptomatic quarantined patients in Codogno, Italy. Radiology [internet]. 2020 Mar;201102. Disponible en: http://pubs.rsna.org/doi/10.1148/radiol.2020201102
25. Bajema KL, Oster AM, McGovern OL, Lindstrom S, Stenger MR, Anderson TC, et al Persons Evaluated for 2019 Novel Coronavirus - United States, January 2020. MMWR Morb Mortal Wkly Rep. 2020;69(6):166-70.

26. Yang W, Yan F. Patients with RT-PCR-confirmed COVID-19 and Normal Chest CT [internet]. 2020 [citado: 2020 mar. 27]. Disponible en: https://www.thelancet.com/ action/showPdf?pii=S2213-2600\%2820\%2930103-X

27. Chen N, Zhou M, Dong X, Qu J, Gong F, Han Y, et al. Epidemiological and clinical characteristics of 99 cases of 2019 novel coronavirus pneumonia in Wuhan, China: a descriptive study. Lancet. 2020;395(10223):507-13.

28. Shi H, Han X, Jiang N, Cao Y, Alwalid O, Gu J, et al. Radiological findings from 81 patients with COVID-19 pneumonia in Wuhan, China: a descriptive study. Lancet Infect Dis. 2020;20(4):425-34.

29. Yang W, Yan F. Patients with RT-PCR-confirmed COVID-19 and Normal Chest CT [internet]. 2020 [citado: 2020 mar. 27]. Disponible en: https://pubs.rsna.org/doi/pdf/10.1148/ radiol.2020200702

30. Wu C, Chen X, Cai Y, Xia J, Zhou XX, Xu S, et al. Risk factors associated with acute respiratory distress syndrome and death in patients with coronavirus disease 2019 pneumonia in Wuhan, China. JAMA Intern Med [internet]. 2020 [citado: 2020 jun. 22]. Disponible en: https://jamanetwork.com/journals/jamainternalmedicine/fullarticle $/ 2763184$

31. Alocución del Director General de la OMS en la rueda de prensa para las misiones diplomáticas sobre la COVID-19 celebrada el 26 de febrero de 2020;[internet]. [citado: 2020 mar. 26]. Disponible en: https://www.who.int/es/dg/speeches/detail/who-directorgeneral-s-opening-remarks-at-the-mission-briefing-on-covid-19---26-february-2020

32. Tan SS, Yan B, Saw S, Lee CK, Chong AT, Jureen R, et al. Practical laboratory considerations amidst the COVID-19 outbreak: early experience from Singapore. J Clin Pathol [internet]. 2020. Disponible en: http://www.ncbi.nlm.nih.gov/pubmed/32198190

33. Udugama B, Kadhiresan P, Kozlowski HN, Malekjahani A, Osborne M, Li VYC, et al Diagnosing COVID-19: The disease and tools for detection [internet]. 2020;14:3822-35

34. Simpson S, Kay FU, Abbara S, Bhalla S, Chung JH, Chung M, et al. Radiological Society of North America Expert Consensus Statement on Reporting Chest CT Findings Related to COVID-19. Endorsed by the Society of Thoracic Radiology, the American College of Radiology, and RSNA. Radiol Cardiothorac Imaging [internet]. 2020;2(2):e200152. Disponible en: http://pubs.rsna.org/doi/10.1148/ryct.2020200152

35. Recursos COVID-19 - Instituto Británico de Radiología [internet]. [citado: 2020 mar. 27]. Disponible en: https://www.bir.org.uk/useful-information/covid-19-resources.aspx

36. Mossa-Basha M, Meltzer CC, Kim DC, Tuite MJ, Kolli KP, Tan BS. Radiology department preparedness for COVID-19: Radiology scientific expert panel. Radiology [internet]. 2020 Mar;200988. Disponible en: http://www.ncbi.nlm.nih.gov/pubmed/32175814

37. Hansell DM, Bankier AA, MacMahon H, McLoud TC, Müller NL, Remy J. Fleischner Society: Glossary of Terms for Thoracic Imaging. [internet]. 2008;246(3):697-722.

38. The British Institute of Radiology. COVID-19 resources [internet]. Disponible en: https:// www.bir.org.uk/useful-information/covid-19-resources.aspx

39. Bao C, Liu X, Zhang H, Li Y, Liu J. Coronavirus Disease 2019 (COVID-19) CT Findings: A Systematic Review and Meta-analysis. J Am Coll Radiol. 2020;17(6):701.

40. Nakajima K, Kato H, Yamashiro T, Izumi T, Takeuchi I, Nakajima H, et al. COVID-19 pneumonia: infection control protocol inside computed tomography suites. Japanese J Radiol 2020 [internet]. 2020 Mar;1-3. Disponible en: http://www.ncbi.nlm.nih.gov/ pubmed/32185669

41. Wu J, Feng C, Xian X, Qiang J, Zhang J, Mao Q, et al. Novel coronavirus pneumonia (COVID-19) CT distribution and sign features. Zhonghua Jie He He Hu Xi Za Zhi. 2020;43(4):321-6.

42. Chung M, Bernheim A, Mei X, Zhang N, Huang M, Zeng X, et al. CT imaging features of 2019 novel coronavirus (2019-nCoV). [internet]. Radiology. 2020;295(1):202-7. https://doi.org/101148/radiol2020200230

43. Liu K-C, Xu P, Lv W-F, Qiu X-H, Yao J-L, Jin-Feng G, et al. CT manifestations of coronavirus disease-2019: a retrospective analysis of 73 cases by disease severity. Eur J Radiol. 2020;126:108941.

44. Salehi S, Abedi A, Balakrishnan S, Gholamrezanezhad A. Coronavirus Disease 2019 (COVID-19): A systematic review of imaging findings in 919 Patients. Am J Roentgenol. 2020;1-7.

45. Bernheim A, Mei X, Huang M, Yang Y, Fayad ZA, Zhang N, et al. Chest CT Findings in Coronavirus Disease-19 (COVID-19): Relationship to Duration of Infection. [internet]. 2020;200463. https://doi.org/101148/radiol2020200463

46. The British Institut of Radiology. COVID-19 resources [internet]. Disponible en: https://www.bir.org.uk/useful-information/covid-19-resources.aspx

47. BSTI. Thoracic Imaging in COVID-19 Infection [internet]. Marzo. 2020 [citado: 2020 ago. 2]. Disponible en: https://www.bsti.org.uk/media/resources/files/BSTI_COVID-19_Radiology_Guidance_v1_13.03.20_9kzNSRs.pdf

48. Zhong Q, Li Z, Shen X, Xu K, Shen Y, Fang Q , et al. [CT imaging features of patients with different clinical types of coronavirus disease 2019 (COVID-19)]. Zhejiang Da Xue Xue Bao Yi Xue Ban [internet]. 2020;49(1):0. Disponible en: http://www.ncbi. nlm.nih.gov/pubmed/32207591

49. Diagnosis and treatment protocol for novel coronavirus pneumonia (Trial version 7) [internet]. Chinese Med J. 2020;133:1087-95.

50. Pan F, Ye T, Sun P, Gui S, Liang B, Li L, et al. Time course of lung changes on chest ct during recovery from 2019 novel coronavirus (COVID-19) pneumonia. Radiology. 2020;200370. Disponible en: http://pubs.rsna.org/doi/10.1148/ radiol.2020200370 
51. Song F, Shi N, Shan F, Zhang Z, Shen J, Lu H, et al. Emerging Coronavirus 2019-nCoV Pneumonia. Radiology. 2020;200274.

52. Oba Y, Zaza T. Abandoning Daily routine chest radiography in the intensive care unit: meta-analysis. Radiology. 2010;255(2):386-95.

\section{Correspondencia}

Jennifer Richardson Maturana

Carrera 45 \# 79-96, apto. 503

Barranquilla, Colombia

jrichardson@uninorte.edu.co

Recibido para evaluación: 10 de marzo de 2020

Aceptado para publicación: 25 de junio de 2020 